Arq. Bras. Med. Vet. Zootec., v.61, n.1, p.144-148, 2009

\title{
Uso tópico de ketanserina na cicatrização de feridas cutâneas induzidas em equinos
}

\author{
[Topical use of kentaserin on healing of experimentally-induced skin wounds in horses] \\ G. Ribeiro, C.B. Martins, M.A.G. Silva, V.P. Borges, J.C. Lacerda Neto* \\ Faculdade de Ciências Agrárias e Veterinárias - UNESP \\ Via de Acesso Prof. Paulo Donato Castellane, s/n \\ 14884-900 - Jaboticabal, SP
}

\begin{abstract}
RESUMO
Estudou-se a eficácia do uso tópico de ketanserina como promotor da cicatrização de feridas cutâneas induzidas em equinos. As feridas foram produzidas em ambos os metâmeros na região da garupa de oito cavalos adultos, em formato quadrangular, medindo cinco centímetros de lado. Aleatoriamente um dos metâmeros foi escolhido como tratado, permanecendo o contralateral como controle. As lesões do grupocontrole foram lavadas somente com água e detergente neutro e no grupo tratado foi realizado o mesmo procedimento seguido de aplicação tópica de ketanserina. A evolução macroscópica e microscópica do processo cicatricial foi avaliada e a área de cada ferida determinada no decorrer do período experimental. Não foram verificadas diferenças significativas entre as feridas do grupo-controle e do grupo tratado com ketanserina durante 56 dias de avaliação.
\end{abstract}

Palavras-chave: equino, cicatrização, pele, ketanserina

\begin{abstract}
The efficiency of topical use of kentaserin on healing evolution of induced skin wounds in horses was studied. The experimental surgical wounds were made in both sides of the croup of eight adult horses. The wounds were square-shaped measuring $5 \mathrm{~cm}$ of each side. One side was considered control and the opposite one treated. Both control and treated animals were rinsed with water and neutral soap. Additionally, the wound on the treated horses received the topical treatment with ketanserin. Macroscopic and microscopic healing evolution of the wounds was evaluated and their areas were determined during the experimental period. The use of topical ketanserin showed no difference between the control and the treated wounds during a period of 56 days.
\end{abstract}

Keywords: horse, healing, skin, kentanserin

\section{INTRODUÇ̃̃O}

A cicatrização de ferimentos em equinos é, frequentemente, prejudicada pela formação de excessivo tecido de granulação. Esse tecido exuberante pode interromper a cicatrização impedindo a contração da ferida e a epitelização (Engelen et al., 2004).

A ketanserina é o protótipo de uma série de antagonistas da serotonina que bloqueiam competitivamente e seletivamente os receptores

Recebido em 28 de agosto de 2007

Aceito em 24 de outubro de 2009

*Autor para correspondência (corresponding author)

E-mail: jlacerda@fcav.unesp.br
$\mathrm{S}_{2}$, antagonizando os eventos mediados por esses receptores (Lawrence et al., 1995). A ketanserina bloqueia o receptor responsável pela contração da maioria dos músculos lisos vasculares e pela agregação plaquetária induzida pela serotonina principalmente na presença de colágeno, que contribui para a estimulação de fibroblastos, interferindo assim, no processo cicatricial e evitando a granulação excessiva (Foz Filho, 1999). O objetivo do presente estudo foi avaliar a cicatrização de ferimentos induzidos experimentalmente em equinos tratados ou não com ketanserina tópica. 


\section{MATERIAL E MÉTODOS}

Foram utilizados oito equinos adultos, machos e fêmeas, sem raça definida. Os animais foram pré-medicados com acepromazina ${ }^{1}$ na dose de $0,05 \mathrm{mg} / \mathrm{kg}$ de peso vivo, por via endovenosa e a anestesia local foi realizada com solução de lidocaína a $2 \%$ sem vasoconstritor ${ }^{2}$. As lesões cutâneas foram produzidas em ambos os metâmeros na região da garupa, em forma de quadrado com $5 \mathrm{~cm}$ de lado, utilizando-se um molde para a obtenção de lesões uniformes (Fig. 1). Após a incisão com bisturi, a pele e o tecido subcutâneo foram removidos por dissecção utilizando-se tesoura romba e pinça anatômica com dente de rato.

Aleatoriamente, um dos metâmeros foi escolhido como tratado, permanecendo o contralateral como controle. Todas as feridas foram lavadas com água e detergente neutro e posteriormente secas com gaze esterilizada. Após esse procedimento, somente as feridas tratadas receberam a aplicação tópica de ketanserina ${ }^{3}$. Os tratamentos foram realizados duas vezes ao dia durante 28 dias e após esse período, uma vez ao dia até 56 dias.

Foram realizadas avaliações das feridas cutâneas $\operatorname{nos} 1^{\circ}, 3^{\circ}, 7^{\circ}, 14^{\circ}, 21^{\circ}, 28^{\circ}, 35^{\circ}, 42^{\circ}, 49^{\circ}$ e $56^{\circ}$ dias de pós-operatório. Os parâmetros macroscópicos relacionados à evolução do processo cicatricial observados foram: sensibilidade dolorosa, presença de tecido de granulação, secreções, crostas, hemorragia e edema. Esses parâmetros foram estimados em escala de 0 a 3 , sendo que 0 indicava ausência dos parâmetros avaliados, 1 ocorrência em até $30 \%$ da lesão, 2 ocorrência em $30 \%$ a $60 \%, 3$ ocorrência em $60 \%$ a $100 \%$ da lesão. O material destinado à análise histológica foi colhido das bordas das lesões e posteriormente fixado em formaldeído tamponado em solução aquosa a $10 \%$. Esse material foi reduzido a pequenos fragmentos, os quais foram submetidos às técnicas rotineiras de inclusão em parafina, cortados em micrótomo manual e corados com hematoxilina e eosina e também pelo tricrômio de Masson. Os parâmetros avaliados microscopicamente foram: integridade do

\footnotetext{
${ }^{1}$ Acepran 1\% - Univet, São Paulo - SP, Brasil.

${ }^{2}$ Xylestesin 2\% - Cristália, São Paulo - SP, Brasil.

${ }^{3}$ Vulketan gel - Merial, Campinas - SP, Brasil.
}

epitélio, organização do tecido conjuntivo, presença de hemorragia, fibroplasia, hiperplasia epitelial, hiperqueratose, neovasos e tipos celulares presentes.

Nas mesmas ocasiões em que as lesões foram avaliadas, seus contornos foram delineados com o uso de plástico transparente e caneta marcadora para retroprojetor. As feridas demarcadas foram, posteriormente, analisadas, utilizando-se planímetro tipo AOTT, e obtendo-se a área de cada uma, no decorrer da evolução cicatricial. Com esses valores foi possível calcular a porcentagem de contração das feridas em 56 dias de evolução cicatricial, por meio da fórmula: contração = área inicial - área final/área inicial (Matera., 2002). Os valores das áreas das feridas, bem como os valores de contração foram submetidos à análise pelo teste $\mathrm{t}$ pareado, com nível de significância de 5\%. Os parâmetros clínicos mensurados por escores foram analisados pelo teste não paramétrico de Wilcoxon que verifica diferenças entre pares ordenados (Wilcoxon Signed Rank Test).

\section{RESULTADOS E DISCUSSÃO}

À inspeção das feridas, os sinais clínicos iniciais observados no primeiro e no terceiro dias foram: hiperemia do tecido superficial das lesões, nas quais se verificaram os maiores valores de sensibilidade, hemorragia, secreção e edema ao redor da área traumatizada. Schumacher et al. (1992) e D'utra Vaz (1995) observaram características clínicas semelhantes para lesões cutâneas em equinos avaliadas nos primeiros dias após a indução, que foram associadas ao pico da fase inicial do processo inflamatório. As avaliações histológicas das lesões realizadas neste mesmo período estão de acordo com os achados clínicos observados, uma vez que tanto nas feridas controle quanto nas tratadas verificou-se a presença de infiltrado inflamatório severo, predominantemente neutrofílico, interposto por reduzido, porém significativo, número de células mononucleares (Fig. 2A).

Outra característica observada nas primeiras 24 horas após o ato cirúrgico, foi um pequeno aumento dos valores de área das lesões em ambos os grupos experimentais (Tab. 1). Segundo Madison e Gronwal (1992), o processo de contração das feridas ocorre em três fases: 
uma fase inicial, na qual as bordas da ferida apresentam retração centrífuga e a área da lesão aumenta; a seguir, um período de contração rápida em direção ao centro da lesão, e finalmente, quando a ferida está praticamente cicatrizada, o processo torna-se mais lento, deixando a curva de cicatrização na forma de platô. $\mathrm{O}$ aumento da área das lesões registrado logo após o traumatismo se deve, segundo Barber (1990), à associação da perda da tensão ao edema da pele.

Tabela 1. Valores médios de área do grupo tratado e do grupo-controle no decorrer do tempo e porcentagem de contração ao final do experimento

\begin{tabular}{ccc}
\hline $\begin{array}{c}\text { Tempo } \\
\text { (dias) }\end{array}$ & $\begin{array}{c}\text { Área }\left(\mathrm{cm}^{2}\right) \\
\text { Grupo tratado }\end{array}$ & $\begin{array}{c}\text { Área }\left(\mathrm{cm}^{2}\right) \\
\text { Grupo-controle }\end{array}$ \\
\hline 0 & 25,00 & 25,00 \\
\hline 1 & 25,50 & 26,39 \\
3 & 23,21 & 24,29 \\
7 & 18,78 & 23,13 \\
14 & 15,84 & 16,68 \\
21 & 11,09 & 11,15 \\
28 & 7,33 & 7,85 \\
35 & 5,91 & 5,42 \\
42 & 3,84 & 3,79 \\
49 & 2,80 & 2,86 \\
56 & 2,06 & 1,91 \\
\hline$\%$ & $91,8 \%$ & $92,4 \%$ \\
\hline
\end{tabular}

Verificou-se no exame das lesões, realizado no sétimo dia, ausência de hiperemia, sensibilidade e hemorragia, além de edema discreto; microscopicamente notou-se ausência do infiltrado inflamatório presente nas avaliações anteriores. Tais achados caracterizam o final da fase inflamatória aguda descrita por Stashak (1991) e Silver (1982). Também a partir do sétimo dia, iniciou-se um período de grande contração, com considerável redução da área das lesões, caracterizando a fase de contração rápida que se estendeu até vinte e oito dias. Em seguida, iniciou-se a fase de contração lenta.

Segundo Lawrence et al (1995), mais de 50\% da cicatrização de um ferimento parece ocorrer por contração, que ocorre em maior proporção na primeira metade do período de cicatrização. Essa observação corresponde aos achados deste trabalho, no qual as lesões foram avaliadas durante oito semanas e apresentaram um período de contração mais acentuado até quatro semanas, quando as feridas já haviam cicatrizado aproximadamente $70 \%$ da área inicial.

Neste trabalho não foi verificada a presença de tecido de granulação visível em nenhum momento das avaliações (Fig. 3). No entanto, há evidências histológicas a partir de 14 dias que caracterizam a fase de granulação, como intensa fibroplasia e neovascularização (Fig. 2B). Segundo Engelen et al. (2004), alguns fatores são responsáveis por promover a hipergranulação tecidual, entre eles: a localização da lesão (as partes mais baixas dos membros são mais predispostas), a mobilidade da região, a perfusão tecidual prejudicada, as infecções e os traumas. Diante do exposto, é possível compreender porque a hipergranulação não foi observada nessa avaliação, uma vez que não estava presente nenhum dos fatores predisponentes.

Ao final das observações, verificou-se não haver diferença significativa na velocidade de cicatrização entre o grupo tratado e o grupocontrole (Tab. 1 e Fig. 3). Este achado difere dos obtidos em outros trabalhos que tiveram resultados positivos (Roelens, 1989; Engelen et al., 2004; Malinin et al., 2004), mas é semelhante aos resultados de Lawrence et al. (1995), que apontaram como explicação mais provável para a ausência do efeito benéfico da ketanserina o fato de terem estudado feridas não associadas a um comprometimento sanguíneo e localizadas em regiões com excelente circulação. Em casos como estes, as feridas cicatrizam normalmente, e a ketanserina não é capaz de reduzir o período de cicatrização além do normal. Em contraste, outros trabalhos que apresentaram efeito benéfico da ketanserina, estudaram feridas crônicas, localizadas em regiões periféricas ou em pacientes com problemas circulatórios (Roelens, 1989; Engelen et al., 2004; Malinin et al., 2004).

Diante do exposto, pode-se afirmar que a aplicação tópica do produto à base de ketanserina utilizado neste estudo (Vulketan gel ${ }^{\mathbb{}}$ ) não produziu resultados significativos como promotor de cicatrização de feridas cutâneas induzidas na região da garupa de equinos. 


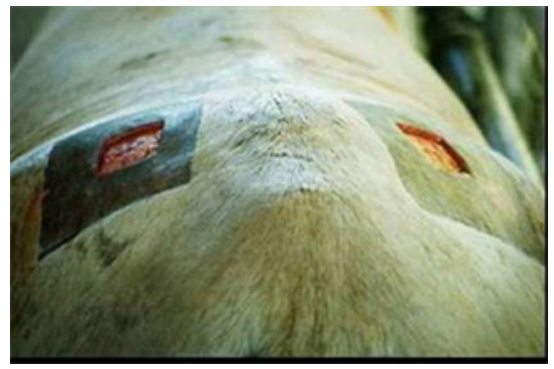

Figura 1. Ilustração fotográfica da região da garupa de um equino adulto, na qual se observam as feridas cutâneas induzidas.
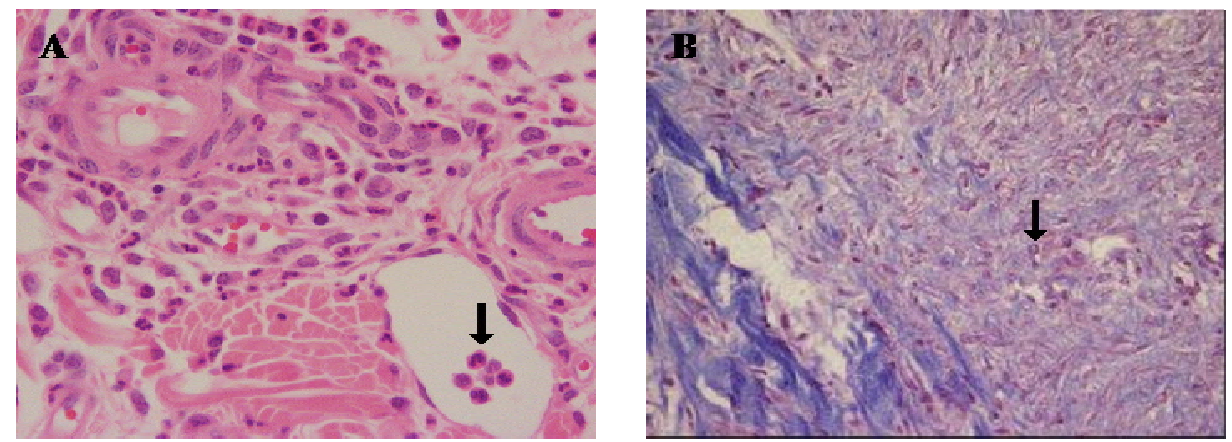

Figura 2. Fotomicrografias ilustrando em A: lesão tratada com ketanserina, com 24 horas de evolução cicatricial. Região com infiltrado inflamatório predominantemente neutrofílico. Observar a presença de neutrófilo (seta) (HE, 100x). B: lesão do grupo-controle com 14 dias de evolução cicatricial. Região de intensa fibroplasia. Observar a coloração azul mais suave, a desorganização do colágeno recém formado e a presença de fibroblasto (seta) (TM, 40x).
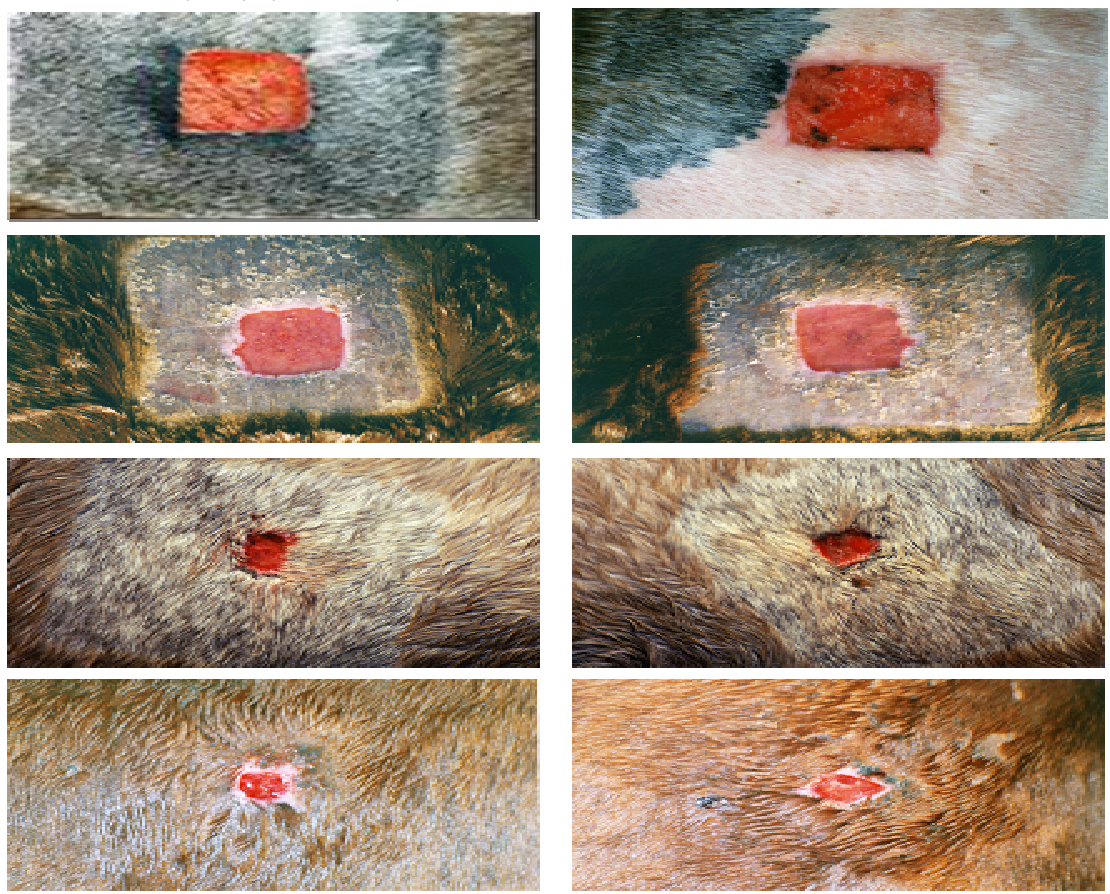

Figura 3. Ilustrações fotográficas nas quais se observam à esquerda as lesões do grupo-controle e à direita as lesões tratadas com 7, 14, 35 e 56 dias de evolução cicatricial. 


\section{REFERÊNCIAS BIBLIOGRÁFICAS}

BARBER, S.M. Second intention wound healing in the horse: The effect of bandages and topical corticosteroids. Proc. Annu. Conv. Am. Equine Pract., v.35, p.107-116, 1990.

D'UTRA VAZ, B.B. Evolução cicatricial de feridas cutâneas induzidas experimentalmente na espécie equina tratadas ou não com película de celulose. 1995. 56f. Dissertação (Mestrado) Faculdade de Ciências Agrárias e Veterinárias, Universidade Estadual Paulista, Jaboticabal, SP.

ENGELEN, M.; BESCHE, B.; LEFAY, M.P. et al. Effects of ketanserin on hypergranulation tissue formation, infection, and healing of equine lower limb wounds. Can. Vet. J., v.45, p.144149, 2004.

FOZ FILHO, R. Feridas cutâneas. Rev. Saúde Equina, v.10, p.10-11, 1999.

LAWRENCE， C.M.; MATTHEWS， J.N.S.; COX, N.H. The effect of ketanserin on healing of fresh surgical wounds. Br. J. Dermatol., v.132, p.580-586, 1995.

MADISON, J.B.; GRONWALL, R.R. Influence of wound contraction in horses. Am. J. Vet. Res., v.53, p.1575-1578, 1992.
MALININ, A.; OSHRINE, B.; SEREBRUANY, $\mathrm{V}$. Treatment with selective serotonin reuptake inhibitors for enhancing wound healing. Med. Hypotheses, v.63, p.103-109, 2004.

MATERA, J. Ensaio de avaliação de eficácia e de exequibilidade de uso do creme ou gaze impregnada com Triticum vulgare em feridas cutâneas. Artigos técnicos em série da ScheringPlough Coopers, n. 8, p.1-7, 2002.

ROELENS, P. Double-blind placebo-controlled study with topical $2 \%$ ketanserin ointment in the treatment of venous ulcers. Dermatologica, v.178, p.98-102, 1989.

SCHUMACHER, J.; BRUMBAUGH, G.W.; HONNAS, C.M. et al. Kinetics of healing of grafted and nongrafted wounds on the distal portion of the forelimbs of horses. Am. J. Vet. Res., v.53, p.1568-1571, 1992.

SILVER, I.A. Basic physiology of wound healing in the horse. Equine Vet. J., v.14, p.7-15, 1982.

STASHAK, T.S. Equine wound management. Philadelphia: Lea \& Febiger, 1991, 278p. 